\title{
Nasogastric tube placement using a semi-rigid esophageal stethoscope in an intubated surgical patient
}

\author{
Sung-Hoon Kim, Dong-Min Jang, and Ji-Hyun Park \\ Department of Anesthesiology and Pain Medicine, Asan Medical Center, University of Ulsan College of Medicine, Seoul, Korea
}

\begin{abstract}
Although nasogastric tube insertion is routinely indicated in patients undergoing abdominal surgery, insertion of a nasogastric tube in anesthetized and intubated patients is associated with a failure rate of $\sim 50 \%$ during the first attempt and has been the cause of delays in beginning surgery $[1,2]$. In this respect, various techniques had traditionally been proposed to facilitate nasogastric tube insertion, including the use of a slit endotracheal tube, lateral neck pressure, head flexion, gloved finger steering, and the use of Magill forceps. More recently, esophageal guidewires and visualization-aided modalities such as the GlideScope were suggested to facilitate nasogastric tube insertion [2,3]. However, these instruments are not always available in the operating room. We suggest that a semi-rigid esophageal
\end{abstract}

stethoscope with a temperature sensor, which is always available in all operating rooms, can safely and effectively aid nasogastric tube placement. In our method, the 18 Fr nasogastric tube is inserted via the nostril and pulled out via the mouth. The nasogastric tube can then be introduced with the assistance of an $18 \mathrm{Fr}$ esophageal stethoscope (Sewoon Medical, Cheonan, Korea) tied to the tip of the nasogastric tube with a $75 \mathrm{~cm}$ surgical suture (size 3-0) by a slipknot, such as the highwayman's hitch [4]. When the nasogastric tube is inserted into the esophagus as deeply as possible, the slipknot can be spontaneously untied with a light tug. We believe that this novel and easy-to-learn method will allow for the successful, safe, and rapid placement of nasogastric tubes in anesthetized patients.

\section{References}

1. Bong CL, Macachor JD, Hwang NC. Insertion of the nasogastric tube made easy. Anesthesiology 2004; 101: 266.

2. Kirtania J, Ghose T, Garai D, Ray S. Esophageal guidewire-assisted nasogastric tube insertion in anesthetized and intubated patients: a prospective randomized controlled study. Anesth Analg 2012; 114: 343-8.

3. Moharari RS, Fallah AH, Khajavi MR, Khashayar P, Lakeh MM, Najafi A. The GlideScope facilitates nasogastric tube insertion: a randomized clinical trial. Anesth Analg 2010; 110: 115-8.

4. Animated Knots by Grog. Highwayman's Hitch. Grog LLC, Texas. 2013. Available from http://www.animatedknots.com/highwaymans. Retrieved 18 May 2014.

\footnotetext{
Corresponding author: Sung-Hoon Kim, M.D., Department of Anesthesiology and Pain Medicine, Asan Medical Center, University of Ulsan College of Medicine, 388-1, Pungnap-dong, Songpa-gu, Seoul 138-736, Korea. Tel: 82-2-3010-3868, Fax: 82-2-3010-6790, E-mail: shkimans@amc.seoul.kr (c) This is an open-access article distributed under the terms of the Creative Commons Attribution Non-Commercial License (http:// creativecommons.org/licenses/by-nc/3.0/), which permits unrestricted non-commercial use, distribution, and reproduction in any medium, provided the original work is properly cited.
} 